\title{
Optimal partisan gerrymandering
}

\author{
GUILLERMO OWEN \\ Department of Mathematics, Naval Post-Graduate School, and \\ Scbool of Social Sciences, University of California, Irvine CA 92717, USA
}

AND

Bernard Grofman

School of Social Sciences, University of California, Irvine CA 92717, USA

\begin{abstract}
We look at the problem of devising an optimal gerrymander from the standpoint of the political party in control of the redistricting process in a singlemember district system involving two-party competition. In an electoral universe with uncertainty, we show that the optimal partisan gerrymander is different from the classic recipe for partisan gerrymandering if parties are concerned with the long-run risk of electoral defeat caused by shifting electoral tides. We look at two different plausible objective functions: (1) maximizing expected seat share: and (2) maximizing the probability of a (working) legislative majority. In general. the optimal districting schemes which will be generated under these two objective functions will be different, although both will make similar use of the two basic gerrymandering techniques, the concentration gerrymander and the dispersal gerrymander. Also, because of the need to minimize risk, both will resemble a bipartisan gerrymander considerably more than has previously been suggested in the literature. We also look at difficulties in achieving either objective (1) or objective (2) because of conflicts between majority party legislators' own selfinterest and the districting that will maximize party advantage, and briefly review evidence that the 1982 California congressional plan was a risk-minimizing partisan gerrymander.
\end{abstract}

\section{Introduction}

The US Supreme Court has long held that gerrymandering for racial discrimination purposes is unconstitutional (Gomillion v. Lightfoot 364 US 399 (1960)). In 1986, for the first time, the Supreme Court held that intentional partisan gerrymander was also unconstitutional if the electoral system was such as to 'consistently degrade a voter's or a group of voters' influence on the political process as a whole', and if the effects of a plan 'are sufficiently serious to require intervention by the federal court' (Davis v. Bandemer $106 \mathrm{~S}$ Ct 2798 at 2810,2811 ). 
The Supreme Court ruling in Bandemer did not have a single majority opinion, and a clear reading of its import is not easy. At minimum, however, it is clear that the question of how to define and measure a gerrymander will play a crucial role in 1990s redistricting litigation. This paper is intended to contribute to the understanding of the art of partisan gerrymandering by showing how potential electoral uncertainties influence the way in which district lines will be drawn for partisan advantage. The focus of this paper is the question, 'If a party wishes to maximize its expected seat share, how should it proceed to draw district lines?'

The answer to that question depends upon the assumptions we make as to the willingness of a political party to tolerate risk and its potential flexibility as to the drawing of district lines. There are three basic components to gerrymandering (see, for example, Sickels, 1966; Gudgin and Taylor, 1979; Grofman and Scarrow, 1982; Owen and Grofman, 1982; Grofman, 1981, 1985c; Cain, 1984, 1985): the concentration gerrymander (concentrating one's opponent's strength in districts which it will capture by huge majorities); the dispersal gerrymander (spreading one's opponent's strength in such a way as to deny it majority control of as many districts as possible); and the incumbent displacement gerrymander (eliminating the seats held by the members of the opposing party and combining the homes of opposing party incumbents into a single district) (Cain, 1985). In this paper we focus on the use of the first two techniques. We recognize, however, as Cain (1985) and Grofman (1985b) have argued that, when used, incumbent displacement may be an even more powerful tool for partisan advantage than either of the first two techniques because, in the United States, incumbents have a considerable reelection advantage. Thus, eliminating incumbents of the other party can considerably increase the ability of a party to translate its votes into seats. We return to a discussion of the importance of incumbent displacement in the final section of the paper.

If we assume that the geographic distribution of partisan support is such that we can find district lines which give us any desired (aggregate) distribution of that party's strength across the districts, and if party identification (perhaps combined with other information such as precinct-level data on previous voting behavior) offers a perfectly accurate predictor of voting outcomes in any (hypothetical) district, then the party in a position to gerrymander should simply draw district lines so as to concentrate its opponent's strength in as many districts as are needed to permit itself bare majorities in all the remaining districts. By dispersal gerrymandering alone, a majority party can achieve bare majorities in all districts. By a combination of the dispersal and concentration gerrymandering techniques a party which expects to have only a minority share of the popular vote (greater than 25 percent), but which is somehow in control of the districting process, can still gain a majority of seats by simply allowing its opponent overwhelming control of some districts in which much or all of the opponent's strength will be wasted.

For a world without uncertainty, we show in Figure 1 the maximum gerrymandering possibilities for the party in complete control of the districting process. Of course, the assumption we have made as to the certainty of a party's vote in any given district is highly unrealistic. A party which provides itself only bare majoritics may do wcll in the short run but is apt to be unpleasantly surprised by the election returns. As Charles Merriam wrote of the gerrymander as long ago as 1922, "The shifts in party vote make it a dangerous practice, which sometimes recoils on the heads of those who undertake it' (cited in Sickels, 1966: 1303). For example, Scarrow (1982a) has shown how a partisan gerrymander in New York failed to achieve the objective of long-run partisan advantage because the party in charge of the redistricting failed to take into account the eventual inter-election shifts in voter choice and tried to skate on 'too thin' majorities. In a similar fashion, Scarrow (1982b) shows how 


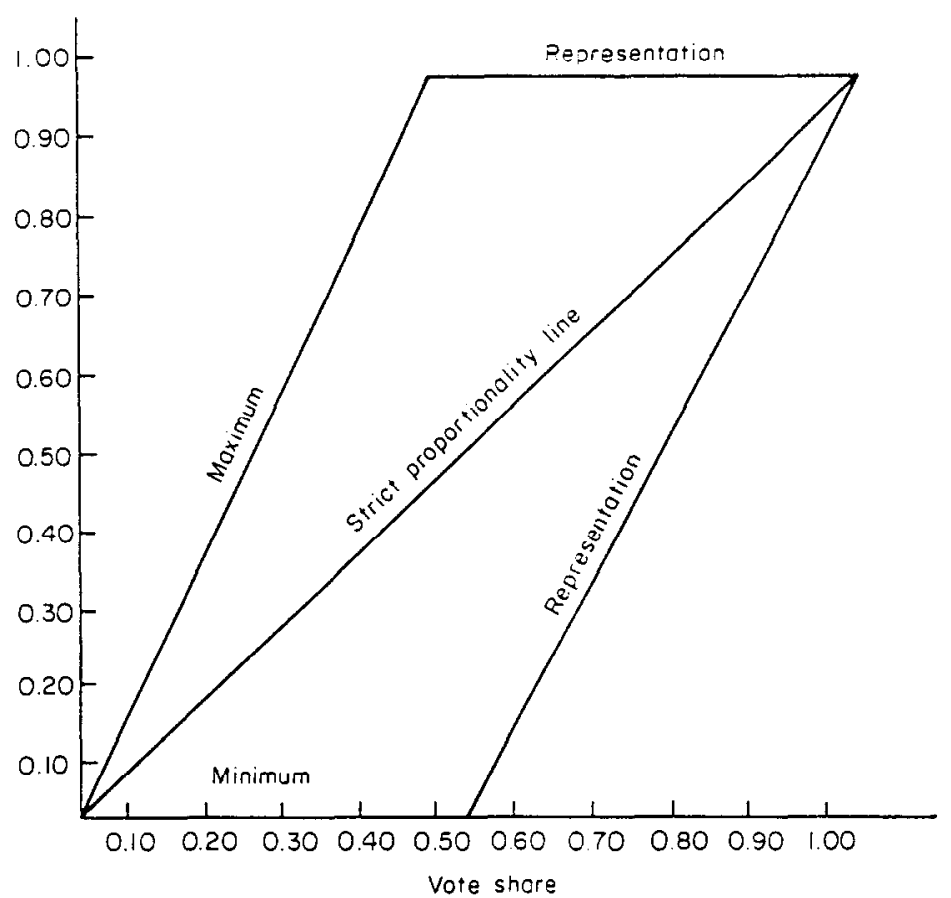

FIGURE 1. Graph of theoretical maximum/minimum seat shares in a two-party single-member district election. Source: Grofman (1975: Figure 6).

Connecticut's 'bipartisan' gerrymander became unglued in the course of a decade, again because of inter-election shifts in voter behavior.

However, a party which is risk-averse can combine the techniques of concentration and dispersion gerrymandering to capture fewer districts (although still a majority of the seats) but with wider margins in those that it wins. Thus, we can talk of sopbisticated political gerrymandering as gerrymandering which is intended to remain in place throughout a decade, regardless of minor fluctuations in a party's aggregate voting support.

In the next sections of the paper we look at sophisticated 'optimal' gerrymandering in an electoral universe with uncertainty in it. We look at two cases of interest. In the first case the party in control of the districting is assumed to want to maximize its expected seat share. In the second case the party in control of the districting is assumed to want to maximize the probability that it will control a voting majority in the legislature. In general, these two objectives will not lead to the same districting decisions, although both will make very similar use of the concentration and dispersal gerrymandering techniques. Moreover, both objective functions will lead to strategies for sophisticated optimal partisan gerrymandering which differ from the classic 'recipe' of seeking to control as many districts as possible by paper-thin margins.

\section{Case I. Maximizing the expected number of seats}

In this section of the paper we consider the problem of maximizing a party's expected seat share in a two-party competition involving single-member districts, where one party (which we label Party I and which need not expect to be the majority party in the future) has control over redistricting, but electoral outcomes instead of being deterministic have a probabilistic component. For an election at time $t$, we posit a random variable $Z_{t}$ and number, $\alpha_{j}$, which 
characterizes the $j$ th district. The party carries all districts $j$ such that $\alpha_{1}>Z_{i}$, loses districts $j$ such that $\alpha_{j}<Z_{t}$. (Presumably the probability that $Z_{t}=\alpha_{j}$ is zero, or at least so small as to be safely neglected.) The number $Z_{t}$ is a random variable with a steady long-term distribution $H(z)$. The quantities $\alpha_{j}$ reflect characteristics of the given districts, representing (in some sense) the general favor or disfavor in which the voters of a given district hold the party. By gerrymandering, these numbers can be changed. We assume, however, that their mean is fixed; i.e. you can change the district boundaries but you cannot change the people.

Let $y(x)$ be the number of $j$ (districts) such that $\alpha_{j}=x$. We have then the constraints:

$$
\begin{aligned}
& \sum_{x} y(x)=N \\
& \sum_{x} x y(x)=A \\
& y(x) \geqslant 0 \quad \text { for all } x,
\end{aligned}
$$

where $N$ is the tutal number of districts and $A$ is a measure of the relative size of the support coalitions for Party I and Party II. There will normally be some bounds on $x$ (e.g. $-1 \leqslant x$ $\leqslant 1$ ). Apart from this, $y(x)$ must be an integer, and there will under certain circumstances be some additional constraints; e.g. it might be impossible to have more than a very small number of districts with extreme values of $\alpha_{j}$. However, we disregard such constraints and assume that the only constraints are (1), (2), (3), where the sums in (1) and (2) are taken over real values of $x,-1 \leqslant x \leqslant 1$, and where (3) holds for all $x,-1 \leqslant x \leqslant 1$.

The long-term probability of carrying the $j$ th district is simply $H\left(\alpha_{j}\right)$. Thus, the longterm expected number of seats won is given by

$$
E[S(y)]=\sum_{x} y(x) H(x)
$$

and we wish to maximize (4) subject to the constraints (1), (2) and (3).

This is a semi-infinite linear program. Its dual would be to minimize

$$
\mathrm{Nu}+\mathrm{Av}
$$

subject to

$$
u+x v \geqslant H(x) \text { for all } x .
$$

Since the dual problem has only two variables, it follows that the primal problem (1)-(4) has a solution such that, at most, two of the variables $y(x)$ are different from zero; i.e. an optimal gerrymander strategy will generally consist of setting one set of districts at one level and the remaining districts at another level of 'support' for the party. In the most common case, the opposition is given an overwhelming majority in a small number of districts, while Party $I$ is given a healthy majority in a much larger number of districts. The exact numbers will, of course, depend on $N, A$, and the function $H$.

To simplify the analysis, we assume that $A=0$. This represents no loss of generality inasmuch as it can be accomplished, if necessary, merely by shifting the value of $x$ by the amount $A / N$. We also set $N=1$; the numbers $y(x)$ are then not numbers of seats, but a fraction of the total number of seats. We have then the two programming problems:

Maximize

$$
\Sigma_{y}(x) H(x)
$$


subject to

$$
\begin{aligned}
\sum y(x) & =1 \\
\sum x y(x) & =0 \\
y(x) & >0 \quad \text { for all } x,
\end{aligned}
$$

and minimize

$$
u
$$

subject to

$$
u+x v \geqslant H(x) \text { for all } x .
$$

We can solve the dual problem without too much difficulty. Constraint (12) reduces to:

$$
u \geqslant H(x)-v x \text { for all } x,
$$

and so the minimal $u$, for a given $v$, must be

$$
u=\operatorname{Max}_{x}\{H(x)-v x\} .
$$

Assuming $H(x)$ to be differentiable, with derivative

$$
b(x)=\frac{d H}{d x}
$$

we see that (under the restriction $-1 \leqslant x \leqslant 1$ ) the maximum can be obtainable only at some point $x$ such that one of the following three conditions holds:

(i) $b(x)=v$

(ii) $x=-1, b(-1) \leqslant v$

(iii) $x=+1, b(1) \geqslant 0$.

This gives us three possibilities for $u$ as a function of $v$ :

$$
\begin{aligned}
& H\left(b^{-1}(v)\right)-v b^{-1}(v) \\
u(v)= & H(-1)+v \\
& H(1)-v
\end{aligned}
$$

In most cases, we would expect $h(-1)$ and $h(+1)$ both to be very small-corresponding to the idea that large swings are infrequent. Thus case (iii) will seldom be applicable. Hence we look at what happens if only cases (i) and (ii) can hold. Here the minimum will be obtained where the corresponding two values of $u(v)$ coincide, so that

$$
H\left(b^{-1}(v)\right)-v b^{-1}(v)=H(-1)+v
$$

or equivalently, if $v=b(x)$

$$
H(x)-x b(x)=H(-1)+b(x),
$$

which reduces to

$$
H(x)-(x+1) b(x)=H(-1) .
$$


This equation (17) has a root $x^{*}$, normally greater than 0 . The optimal gerrymander then requires

$$
\begin{aligned}
& y(-1)=\frac{x^{*}}{1+x^{*}} \\
& y\left(x^{*}\right)=\frac{1}{1+x^{*}}
\end{aligned}
$$

with $y(x)=0$ for all other $x$; i.e. a fraction $\frac{x^{*}}{1+x^{*}}$ of all districts will be overwhelmingly for the opposition $\left(\alpha_{j}=-1\right)$, while the complementary fraction $\frac{1}{1+x^{*}}$ of the districts will be solidly for Party I $\left(\alpha_{j}=x^{*}>0\right)$. Thus, for this type of optimal gerrymander, we have a situation in which both parties have seats which are usually won by large numbers, but (slightly) more seats for the party doing the gerrymandering.

Since $x^{*}<1$ in the usual case, this means Party I will, in the majority of cases, hold a solid majority of seats. Its expected number of seats will then be ${ }^{1}$

$$
E[S(y)]=\frac{x^{*} H(-1)+H\left(x^{*}\right)}{1+x^{*}} .
$$

Case II. Maximizing the probability of controlling a (working) majority of seats

As opposed to maximizing expected numbers of seats, let us now consider the problem of designing a sophisticated gerrymander so as to maximize the probability that the controlling party will obtain a (working) majority of the seats in the legislature, defined as $k$ seats out of a total of $n$ seats. We do not assume that $k$ need be a bare majority; rather, we assume simply that $k$ is whatever Party I may consider a working majority. The exact size of this would of course depend on the likelihood of defections, unavoidable absences, etc.

In the simplest case, we assume as before a number $\alpha$; which characterizes each district. As before, we posit that the party will carry the $j$ th district (almost certainly) if $Z<\alpha_{j}$. We may show that for this case it will be optimal to make $\alpha_{j}$ uniformly as large as possible for $k$ of the districts, and very small for the remaining $n-k$ districts. Assuming the restrictions (8)-(10) given in Case I above, the optimal gerrymander would now be given by

$$
\begin{aligned}
& y(\hat{x})=\frac{k}{n} \\
& y(-1)=1-\frac{k}{n} \\
& y(x)=0 \quad \text { for all other } x
\end{aligned}
$$

where

$$
\hat{x}=\frac{n-k}{k} \text {. }
$$

The probability of obtaining a (working) majority of seats is then $H(\hat{x})$, where $H$ is as before. Again, as we see in the example discussed below, this results in a districting scheme with a considerable bimodality-making it look much like what might be expected under a bipartisan districting scheme. 
This analysis is valid so long as it is assumed that there is a strong positive correlation in the year-to-year swings in votes between legislative districts. In a somewhat different model, we might envision a situation in which the swings in the several districts were totally uncorrelated. In this case, it can be shown (the proof is a straightforward adaptation of a theorem given in Grofman et al., 1983) that an optimal gerrymander calls for strengthening the party equally in a certain number of districts; i.e. we would have

$$
y(\hat{x})=\frac{r}{n}
$$

and

$$
y(-1)=1-\frac{r}{n}
$$

where $r \geqslant k$. In other words, the party would be given very strong majorities in $r$ of the districts. It is difficult, however, to specify analytically the exact value of $r$ : all that can be said with certainty is that $r \geqslant k$.

\section{An illustration of the two objective functions} and the optimal gerrymanders they give rise to

As an example, let us assume that the variable $Z$ has a normal distribution with mean 0 and standard deviation $1 / 2$. Then $H(x)=\Phi(2 x)$, where $\Phi$ is the cumulative standard normal distribution, while $b(x)=2 \varphi(2 x)$, where $\varphi$ is the normal density function. Equation (17) then takes the form

$$
\Phi(2 x)-2(x+1) \varphi(2 x)=\Phi(-2)
$$

or

$$
\Phi(2 x)-2(x+1) \varphi(2 x)=0.02 \text {. }
$$

This equation cannot be solved analytically, but numerically it is found to have the approximate solution

$$
x^{*}=0.42 \text {. }
$$

Then (18) and (19) take the form

$$
\begin{gathered}
y(-1)=\frac{0.42}{1.42}=0.30 \\
y(0.42)=\frac{1.00}{1.42}=0.70 .
\end{gathered}
$$

Thus an optimal gerrymander (in the sense of maximizing the expected number of seats) would be obtained by giving the dominant party a strong majority $(x=0.42)$ in 70 percent of the districts, while the other party would be given an overwhelming advantage $(x=-1)$ in the other 30 percent of the districts.

Suppose, on the other hand, that the dominant party's principal interest lies in controlling the legislature. We might assume 'working control' means 52 percent of the seats. In that case, equation (24) takes the form

$$
\hat{x}=\frac{0.48}{0.52}=0.92
$$


while $(21-22)$ take the form

$$
\begin{gathered}
y(\hat{x})=0.52 \\
y(-1)=0.48 .
\end{gathered}
$$

Thus the dominant party would give itself an overwhelming majority in 52 percent of the districts, giving the other party an even stronger majority in the remaining 48 percent. (This is of course necessary since, by hypothesis, the parties are originally on an even footing, symbolized by the fact that $Z$ has mean 0 .)

To see the difference in these two plans, we note that in the first case (expected seat maximization) the dominant party will usually control 70 percent of the seats. Once in a while, however (probability 0.2 ), a landslide will wipe out the party. There is finally a very small probability (0.02) that a landslide in the dominant party's favor will give them all the seats. Thus, the dominant party will have 0,70 percent or 100 percent of the seats with probabilities $0.20,0.78$ and 0.02 , respectively, and its expected number of seats is 56.6 percent.

In the second case, the dominant party will usually control 52 percent of the seats. There is, however, a slight probability (0.03) of a landslide in which the dominant party loses all its seats, and a very small probability $(0.02)$ that the dominant party will win all the seats. Thus it will have 0,52 percent or 100 percent of the seats with probabilities $0.03,0.95$ and 0.2 . respectively, and its expected number of seats is 51.5 percent.

In brief, then, the first plan gives the dominant party a substantially higher expectation, 56.6 versus 51.4 percent of the seats under the second plan. On the other hand, the dominant party's majority is much safer in the second case: it will control the Legislature 97 percent of the time, versus only 80 percent of the time under the first plan. It would be up to the party leaders and strategists to decide which of the two objectives to emphasize.

\section{Achieving near-proportional representation through a single-member district plan}

Redistricting might also be carried out for other than partisan reasons - might, indeed, be aimed at achieving a fair partisan balance. Proponents of a 1960 s legislative plan in Connecticut argued that it was aimed at partisan fairness. This claim was upheld by the US Supreme Court in Gaffney v. Cumming 412 US 735 (1973). As an example we could consider the task facing a (nonpartisan) redistricting commission which believes that something like proportional representation would be good for the system. (We ignore the fact that such representation would much more readily be attained through a form of election other than single-member districts: see Grofman, 1975; Lijphart and Grofman, 1984).

To see how this might best be done, we must first study the functional relationship which holds between the random variable $Z_{t}$ described above and the fraction of the total vote, $W_{t}$, obtained by Party I. Presumably, $W$ is a monotone, strictly increasing function of $Z$, but otherwise no assumptions can be made. (It would be nice if $W$ were equal to $Z$, or at least linearly related to $Z$, but in fact things generally do not work out that simply in the real world.) Suppose, then, that we have

$$
W=b(Z) \text {. }
$$

The situation is now as follows: when the random variable $Z$ takes the value $z$, then Party I will receive a fraction $w=h(z)$ of the total vote. We would therefore like the party to carry a fraction $w$ (or as close to this as possible) of the seats in the Legislature. In fact, 
however, it will carry every district $j$ such that $\alpha_{j}<z$. The desired relationship is then

$$
\text { number of }\left\{\int \mid a_{j}<z\right\} \cong n h(z)
$$

where $n$ is the total number of seats. An alternative way of writing this is as follows: if the districts are numbered in order of increasing affinity towards Party I, so that $\alpha_{1} \leqslant \alpha_{2} \leqslant \ldots$ $\leqslant \alpha_{n}$, then we should have

$$
\alpha_{j} \cong b^{-1}(j / n) \text {. }
$$

Two things could conceivably go wrong. First, relation (26) yields

$$
\sum_{j=1}^{n} \alpha_{j} \cong \sum_{j=1}^{n} b^{-1}(j / n),
$$

but constraint (2) can be rewritten as

$$
\sum_{j=1}^{n} \alpha_{j}=A
$$

and unfortunately, there is no a priori reason why the right sides of (27) and (28) should coincide (not even approximately). Apart from that, it may well be that, for small (close to 0 ) or large (close to $n$ ) values of $j, b^{-1}(j / n)$ will be an unattainable value for $\alpha_{j}$. For example, for $n=100, b^{-1}(0.99)$ may be too large a value for $\alpha_{j}$; i.e. it is probably impossible to create a district which Party II will still manage to carry when Party I gets 99 percent of the popular vote.

Given these two considerations, (26) cannot usually be made to hold for all $j$. The redistricting commission might, however, try to make it hold at least for values of $j$ which are close to $n / 2$ : this would give (approximate) proportional representation to the two parties so long as each obtained, say, between 35 and 65 percent of the popular vote, but would badly misrepresent the strength of a party with less than 25 percent of the vote. (In general, such a party would probably be underrepresented.)

\section{Practical constraints on optimal gerrymandering}

There are two important practical constraints in gerrymandering. First, there are geographic constraints on creating all of the mathematically possible distributions of partisan voting strengths across constituencies. Second, the interests of individual legislators and the interests of overall party advantage may come into conflict.

\section{Geograpbic dispersion of partisan voting strength}

The nature of the dispersion of the other party's supporters puts certain constraints on the gerrymander. In theory, it may be possible to put any number of Democrats or Republicans into a district, but this may require drawing district lines that pass through the middle of a bedroom to separate a Republican husband from his Democratic wife, or give rise to districts which resemble amoebas. In practice, however, computer-assisted 'creative cartography' may enable skilled political operatives to draw lines which achieve something very close to an optimal partisan gerrymander. 
Conflicts between individual legislator motivations and overall partisan advantage

Leroy Hardy (1977) has trenchantly argued that those doing redistricting are rarely, if ever, motivated entirely (or even mostly!) by a desire to improve the fortunes of their political party. Hardy (1977: 267) cites one study of state redistricting which concluded that:
... districts were created with the following interests in mind: (a) individual preservation, i.e. the creation of a 'safe' district for incumbents; (b) mutual preservation between incumbents, frequently cutting across party lines; or, in other words, a preservation of the 'club' made up of incumbents of both parties; (c) the preservation of political power by the majority party; and (d) preservation of blocs (such as the 'farm bloc' or the 'rural bloc') in the legislature without regard for party lines.

Hardy (1977:. 269) suggests that the usual view of gerrymandering as a process which political parties use to bolster their power may be 'a gross simplification'.

\begin{abstract}
It assumes a strong political party organization to implement the party will. Legislators who do the redistricting are not prone to commit political hari-kari, but rather are motivated by self-preservation. Only secondarily is their political party's welfare considered.
\end{abstract}

Nonetheless, in an electoral universe with uncertainty, the conflict between legislator selfinterest and aggregate partisan advantage may be minimal. Hardy (1977: 269) asserts that 'though dispersl gerrymanders would probably maximize the party's strength, concentration gerrymanders are favored by the incumbents'. As we show above, if there is enough electoral uncertainty and if party strength is near evenly divided, the distributions which maximize expected partisan advantage (defined in either one of our two ways) may actually be one which looks very much like a bipartisan gerrymander (with concentrated districts for both parties).

\title{
Discussion
}

We have shown that in an electoral universe with considerable uncertainty and practical geographic limitations on creating districts with 100 percent partisan support, the outcome of a partisan, expected seats-maximizing redistricting may look to the outsider much like a bipartisan gerrymander, since it will consist of a number of districts 'safe' for the opposition party and a (perhaps only slightly) larger number of districts with 'healthy' majorities for the (majority) party doing the redistricting. Nonetheless, it will still be a partisan gerrymander, because it will make more efficient use of the voting strength of the party doing the gerrymandering (Cain, 1985).

There is another common kind of gerrymandering-which we might call 'personalized' gerrymandering-in which district lines have been drawn in such a way as to help or hinder the election/reelection chances of particular individuals (see, for example, 'One man, one vote, one mess: as states redistrict, recriminations-and fists-fly', Time, July 13, 1981). While such personalized gerrymandering may be pernicious, we believe (once equalpopulation districting guidelines are satisfied) that the appropriate basis of challenge to redistricting schemes under the 'one-person, one-vote' doctrine is at the level of aggregate 'fairness'-defined as the absence of bias (in the seats-votes relationship) for or against any given political party (or rarial or linguistic group). (For a precise definition of electoral bias see Niemi and Deegan, 1978; Grofman, 1983.) Of course, there is no good reason to gratuitously seek to draw districts so as to force two or more incumbents into the game 
district, and plans which treat unequally incumbents of opposite parties may thereby, ipso facto, be unconstitutional gerrymanders (see Grofman, 1985a,c).

The redistricting strategy(ies) which should be pursued if the aim were to maximize partisan advantage (defined either in terms of expected seat-maximizing or in terms of maximizing the probability of majority legislative control) provide(s) an important baseline against which to compare actual redistrictings; moreover, the partisan-oriented baselines can be used to assess the probable weight of the various elements that comprise majority party legislators' utility functions. However, we must be careful to distinguish between intended and unintended gerrymandering. The Supreme Court in Bandemer has held that only intended gerrymandering is unconstitutional. We have just seen that an 'optimal' gerrymander gives healthy majorities in some districts to the favored party and overwhelming majorities in a smaller number of districts to the other party. Now if this type of concentration occurs naturally (e.g. urban areas with healthy majorities for one party and suburban areas with overwhelming majorities for the other party, or vice versa), the general effect will be similar to an intended gerrymander. The way in which we would distinguish hetween intended and unintended partisan gerrymandering would be to look at the extent to which districts went higgledy-piggledy over the map specifically to pack or fragment partisan concentrations of voters, or unnecessarily violate political subunit integrity or communities of interest.

In our view, it is the partisan consequences (including differential treatment of incumbents of opposite parties) that make a political gerrymander, not irregularly shaped districts per se. As Sickels (1966: 1300) aptly put it:

\begin{abstract}
Majority parties in state legislatures gerrymander ... districts as a matter of course. The electoral maps of many states, particularly the larger ones, are intricate jigsaw puzzles. But inspection of electoral maps for the presence of gerr:manders is hit or miss at best. Dragons, bacon strips, dumbbells, and other strained shapes are not always reliable signs that partisan (or racial or ethnic or factional) interests are being served, while the most regularly drawn district may turn out to have been skillfully constructed with an intend to aid one party. The safest and most direct indication of gerrymandering is a state-wide calculation of results.
\end{abstract}

Of course, as the US Supreme Court made clear in Bandemer, the discrepancy between vote share and seat share in any single election is not, standing alone, a good indication of gerrymandering skill, since such discrepancies may arise from factors idiosyncratic to that election, or unconnected with intentional gerrymandering.

There are three ways that have been proposed to establish a baseline of statewide electoral strength from which to determine whether a given party's vote strength has been fragmented on the one hand, and packed on the other in a particular district-based plane:

1. looking at a party's aggregate share of the statewide (two-party) vote in the districts at issue (Dahl, 1956;. Sickels, 1966; Dixon, 1971: 255);

2. looking at a party's share of the statewide (two-party) vote in a representative set of statewide elections as distributed in the districts at issue (Backstrom et al., 1978);

3 . in states where these data are available, looking at a party's share of the statewide registration (California Democratic Congressional Delegation Reply Brief in Support of the Motion to Dismiss, Badbam v. Eu, ND California, December 1986).

The Supreme Court in Bandemer was confronted with a divided lower cour opinion in that case in which the two judges in the majority calculated baseline Democratic strength by method (1), while the dissenting judge obtained a different (and lower) number by 
amalgamating data from a set of statewide races via method (2). He claimed support for his method because Backstrom et al. (1978) had been favorably cited by Justice Stevens in his concurring opinion in Karcher v. Daggett, 462 US 725 (1983). Because the Supreme Court in Bandemer did not find evidence from a single election sufficient to meet its 'consistent degradation' test, it explicitly refused to decide the question of which of these two methods was the more appropriate (106 S Ct 2797 at $2811-2812$, n. 15 (1986)). ${ }^{2}$

We believe that both methods (1) and (2) can contribute to understanding how a gerrymander has been implemented. Method (3), on the other hand, even though superficially plausible, can provide a totally misleading view of party voting strength, since registration does not translate into votes in a one-to-one fashion. For example, in California, a district which is 50 percent Democratic in (two-party) registration is not competitive but is a safe Republican seat (Grofman, 1985a). Also, if one party uses incumbent displacement gerrymandering to reduce the number of victors of the other party while at the same time increasing its own incumbent advantage, the enhanced advantage in numbers of incumbents will allow the party which gerrymandered to reap more votes. If registration data are to be used, they must be used (as in Cain, 1985) to develop a (multivariate) predictor equation of expected election (or vote) outcomes. In general, registration data will be misleading.

Methods (1) and (2) are useful complements to one another. Method (1) uses the actual sum of the votes received by all candidates of the given party in a set of districts to develop a total vote-strength figure for that party. The advantage is that such a sum is a simple and direct measure of aggregate vote strength; the disadvantage is that it is confounded by idiosyncratic district-specific factors such as incumbency. On the other hand, method (2) seems to require careful judgment about appropriate selection of baseline races and thus may be subject to greater controversy. However, we expect that, in practice, if gerrymandering is severe enough, most reasonable selections of statewide races will reveal the extent to which one party's votes have been more packed and more dispersed across the districts than those of the party doing the gerrymandering.

Neither method (1) nor method (2) is perfect at detecting the effects of gerrymanders. Both methods will almost certainly completely miss the use of incumbent-displacement gerrymandering techniques. Method (1) is especially flawed in this regard. Indeed, when there has been incumbent displacement gerrymandering, unless the incumbency advantage is explicitly built (as in Cain, 1985) method (1) will mis-state the effects of gerrymandering on the seats-votes discrepancy, since the fact that the party which has been gerrymandered against now has fewer incumbents means that it also now has fewer votes, while the party which did the gerrymandering will have more of an incumbency advantage, giving it an expected increase in its vote share. Thus, incumbency displacement will reduce the observed discrepancy between votes and seats by reducing the votes of the party which has its incumbents eliminated by gerrymandering.

Even if we agree on a measure of statewide partisan voting strength (and we can, of course, compare the predictive fit of alternative measures in specific cases), we must still determine what to look for to prove gerrymandering. We believe that electoral bias (Tufte, 1973; Niemi and Deegan, 1978; Grofman, 1984), i.e. asymmetry in the way each party is able to translate its vote strength into seats, is more important than the simple discrepancy between vote share and seat share. Clearly, a 10 percent discrepancy between votes and seats may be quite reasonable if a party with 65 percent of the votes gets 75 percent of the seats. On the other hand, if a party with 45 percent of the votes got 55 percent of the seats, there would be considerable grounds for suspicion (cf. Grofman, 1982). In the latter case the majoritarian criterion (Grofman, 1985c), that the party with a majority of the votes receive a majority of the seats, has been violated. When optimal partisan gerrymandering (as we 
have described it below) takes place, it must create eiectoral bias.

Unfortunately, even measures of electoral bias will also miss (or mistake) the effects of incumbency displacement gerrymandering. Thus, we believe that the detection of gerrymandering requires a combination of techniques. As one of us wrote earlier,

In determining whether partisan gerrymandering has taken place, I would place particular reliance on (1) showing an incumbent-centered partisan bias (i.e., a differential treatment of the incumbents of the two major parties); (2) demonstrating that concentration and dispersion gerrymandering techniques has been used; (3) showing that deviations from compactness and failure to follow political subunit boundaries were systematically linked to probable partisan impacts; and (4) demonstrating that the plan so constrains the probable range of politically competitive seats as to create a near certainty of continued partisan unfairness for the foreseeable future (Grofman, 1985c: 155, footnote omitted).

To show how this might be done, we provide an illustration using data on the California congressional plan drawn up in 1981 under the direction of the late Congressman Philip Burton. This plan is widely recognized by political scientists to be the most dramatic congressional political gerrymander of the 1980s (see, for example, Robertson, 1983; Gopoian and West, 1985; Schwab, 1985). In our empirical analysis, we draw heavily on the work of Cain (1985) and Grofman (1985b).

\section{Incumbent displacement}

We show in Table 1 how 1980 Democratic and Republican incumbents were differentially treated in the Burton plan which went into effect for 1982 only after it had been repudiated by the voters in a referendum. Of the 21 Republican incumbents, six were placed in with incumbents of their own party, one (Dornan) had his seat 'disappear' from under him, and one (Clausen) ran and lost in a seat where Republican voting strength had been marginally reduced (see Grofman, 1985b).

As Cain points out (1985: 331; see also Grofman, 1985c),

[A] proper assessment of the partisan effects of redistricting cannot overlook its impact on incumbency ... [T, the temporary scrambling of incumbents can have momentous importance for the election that follows the redistricting . . [ [ ] $\mathrm{n}$ an area where party loyalty counts for less and incumbence counts for more, redistricting tactics should include incumbent considerations. Indeed, if recent trends toward independence from the parties continue, redistrictings in the future could come to focus more on [incumbent] displacement issues and less on the partisan make up of a district.

\section{Concentration and dispersal gerrymandering}

Cain (1985) provides a clear specification of what sorts of effects we should expect when a partisan gerrymander is instituted following a court-drawn plan.

1. Some number of marginal Democratic seats should have been strengthened.

2. Some number of marginal Republicans should have been weakened.

3. Some number of strong Democrats should have been weakened to assist marginal Democrats.

4. Some number of strong Republicans should have been made even stronger (Cain, 1985: 324). 
TABLE 1. Differential treatment of Republican and Dernocratic 1980 incumbents: Burton I and Burton II

(a) Incumbent preservation and incumbent-seat preservation

\begin{tabular}{lll} 
& \multicolumn{1}{c}{1980} & \multicolumn{1}{c}{1980} \\
1980 & Incumbent put & Incumbent put \\
alone in a & alone in a \\
district, ran & district but did \\
& and won that & not run: seat \\
district in & wonbycandidate \\
1982 & of same party as \\
& & incumbent
\end{tabular}

\begin{tabular}{llll}
\hline $\mathrm{D}$ & 22 & 21 & 1 \\
$\mathrm{R}$ & 21 & 11 & 2
\end{tabular}

(b) Incumbent disadvantaged

\begin{tabular}{|c|c|c|c|c|c|}
\hline & $\begin{array}{l}\text { Elected in } \\
1980\end{array}$ & $\begin{array}{l}\quad 1980 \\
\text { Incumbent put } \\
\text { alone in a } \\
\text { district, ran } \\
\text { and lost that } \\
\text { district in } \\
1982^{\mathrm{a}}\end{array}$ & $\begin{array}{l}\quad 1980 \\
\text { Incumbent put } \\
\text { alone in a } \\
\text { district but did } \\
\text { not run: seat } \\
\text { won by } \\
\text { candidate of } \\
\text { opposite partyc }\end{array}$ & $\begin{array}{l}\quad 1930 \\
\text { Incumbents put } \\
\text { together in a } \\
\text { district with } \\
\text { another } \\
\text { incumbent of } \\
\text { same party }\end{array}$ & $\begin{array}{l}\quad 1980 \\
\text { Incumbents put } \\
\text { together in a } \\
\text { district with } \\
\text { another } \\
\text { incumbent of } \\
\text { opposite party }\end{array}$ \\
\hline $\mathrm{D}$ & 22 & 0 & 0 & 0 & 0 \\
\hline $\mathrm{R}$ & 21 & 1 & 1 & 6 & 0 \\
\hline \multicolumn{2}{|c|}{$\begin{array}{l}\text { (c) Summary } \\
\text { Number of } 1980 \text { incumbents } \\
\text { disadvantaged (or potentially } \\
\text { disadvantaged) by redistricting }\end{array}$} & & & \multicolumn{2}{|c|}{$\begin{array}{l}\text { Number of } 1980 \text { incumbents } \\
\text { helped (or potentially helped) } \\
\text { by redistricting }\end{array}$} \\
\hline Democratic & Republican & & & Democratic & Republican \\
\hline 0 & 8 & & & 22 & 13 \\
\hline
\end{tabular}

For Column 2, Republican seat is Clausen R-2 (becomes Bosco D-1).

b For Column 3, Democratic seat is Burton D-5 (becomes D-6). Republican seats are Burgener R-43 and McCloskey R-12.

c For Column 3, Republican seat is Doman R-27. This seat was cut to pieces.

d For Column 4, Republican seats are Goldwater R-20 and Fiedler R-21 (becoming Fiedler R-21). Moorhead R-22 and Rousselot R-26 (becoming Moorhead R-2), and Grisham R-33 and Dreier R-35 (becoming Dreier R-33). Goldwater chose to run for another office, Rousselot to change districts (he ran unsuccessfully against a Democratic incumbent). Thus, six Republican seats in 1980 were turned into three Republican sests in 1982.

Source: B. Grofman, First Declaration in Badham v. Eu (ND Cal. 1984); Burton II (Table A).

Cain tests these propositions with simple registration data and then using a logit model to predict the estimated probabilities of a Democrat winning each seat, first under the assumption that all seats are open and then in a model which takes into account incumbency effects.

Cain finds support for all four propositions (as does Grofman, 1985b, in a parallel analysis). Cain finds two marginal Democratic seats (John Burton in 5, and George Brown in 36) were strengthened; four marginal Republican seats were weakened or otherwise 
redesigned to provide incumbency removal (Hunter, Fiedler, Dornan and Rousselot), and there were a number of seats that were already strongly Republican which were 'made even more so by the plan' (Cain, 1985: 327). Also, while five Democrats in rather safe seats were made worse off by the Burton plan, 'all had Democratic registrations above 55 percent and with the added advantage of incumbency, they all had a greater than 95 percent chance of being reelected even after their districts were altered' (Cain, 1985: 326).

\section{Deviations from compactness and otber vioiations of standard 'good government' criteria systematically linked to probable partisan impact}

We do not belabor this point. Suffice it to say that California's congressional districts were awarded the (imaginary) 'Elbridge Gerry Award' for the Most Creative Electoral Cartography of the 1980 s by a long-time analyst of the gerrymandering game who had served as a consultant to the California Special Masters in 1973 (Baker, 1985). Moreover, these aberrant features of the pian could almost always be traced to manipulations designed to achieve probable partisan advantage (see Grofman, 1985b).

\section{Eliminating competitiveness so as to lock-in partisan advantage for the foreseeable future}

It is important to appreciate that Burton's skillful 1981 gerrymander was a risk-averse one. It took a situation in which, because of incumbency advantage, there were few competitive seats, and created a situation in which there were virtually no competitive seats; i.e. the Burton plan, on the face of it, looked like a bipartisan gerrymander. For example, the average victory margins of the 28 Democratic victors in 1982 was 64.0 . The average margin of victory of the Republican victors was 66.1 percent. There were only six seats (out of 45) won with a vote of less than 55 percent. Five of those victors were Democratic, only one was Republican. In contrast, in 1980 , there had been 10 competitive seats (out of 43 ), and Republicans had won seven of them; but even then the victory margins of winners were 64.1 percent for Democrats and 65.5 percent for Republicans. As Cain (1985: 331) correctly points out, 'The key to a partisan plan is not simply increasing the average margin of victory or even the underlying partisan strength of all majority-party legislators'. Indeed, neither of these tactics was employed by Burton in his 1981 plan:

\footnotetext{
Rather, the key is increasing the efficiency of majority party strength, which will mean a redistribution of electoral strength for the purpose of maximizing the number of vulnerable seats. Some majority incumbents will get stronger and others weaker in inverse relationship to their initial vulnerability (Cain, 1985: 331, emphasis added).
}

Cain's overall conclusion is that 'the combination of partisan reconstruction and the artful removal of inconveniently placed incumbents can alter the seat distribution and make the majority party more efficiently distributed than the minority party. In the case of California, it was enough to help swing five seats to the Democrats' (Cain, 1985: 331). We would add to this the point that both of the 'new' seats in California were won by Democrats, even though the most massive population growth was in the Republican-leaning areas of the state.

California's 1982 congressional plan (and, we might add, its 1984 successor-to which it was substantively identical in partisan terms; Grofman, 1985b) provides the best illustration of a sophisticated optimal partisan gerrymander of the first type (maximizing expected number of seats) of which we are aware. It is also nearly perfect as an example of a 
sophisticated optimal partisan gerrymander of the second type (maximizing likelihood of continued majority dominance), since it guarantees that control of the California congressional delegation will remain in Democratic hands for the rest of the decade, barring an aggregate pro-Republican vote shift in the order of magnitude of 20 percentage points. In a state where the aggregate Republican two-party vote share has remained very close to 50 percent for the last decade, this is equivalent to saying that the California congressional delegation will remain with a Democratic voting majority until hell freezes over. or until a new and drastically different reapportionment takes place in 1992, or until such time as the present plan is held to be an unconstitutional gerrymander by the Supreme Court (see Badham v. Eu, ND California, 1984).

\section{Acknowledgements}

This research was supported by NSF Grants \# SES 85-15468 and \# SES 81-07554, Political Science Program. We are indebted to the staff of the Word Processing Center, University of California, Irvine, for typing this manuscript, to Sue Pursche for proofreading it, and to Laurel Eaton and Dorothy Gormick for bibliographic assistance. The second author was an expert witness for the State of Indiana in Davis v. Bandemer 106 S Ct 2797 (1986) and is an expert for the Republican National Committee in Badham v. Eu, a pending challenge to California's congressional plan on grounds of political gerrymandering.

\section{Notes}

1. The assumptions we have considered represent clearly far and away the most common case, but under certain circumstances other results may obtain. It is therefore necessary to verify that the constraints (12) hold for all, $x$, i.e. that

$$
u+x b\left(x^{*}\right) \geqslant H(x) \quad \text { for all } x .
$$

If so, then the constraints of both primal and dual programs are satisfied, and so this is the true optimum. If not, a different result may obtain. A different result will also hold in case equation (17) has no positive root $x^{*}$ (or if $x^{*}>1$ ).

As a counterexample to the usual case discussed above, we might consider a case in which $b(1)$ and $b(-1)$ are both large, while $b(x),-1<x<1$, is smaller. (In other words, large swings are, for some reason, more likely than small swings.) In this case, we would find that case (15(ii)) was impossible; thus only cases (15(i)) and (15(iii)) would hold. The minimizing value of $v$ would occur, then, if $v=b\left(x^{*}\right)$, where $x^{*}$ is the root of the equation

$$
H(x)-(x-1) b(x)=H(1),
$$

and would satisfy $-1<x^{*}<0$. The optimal gerrymander would be obtained by setting

$$
y\left(x^{*}\right)=\frac{1}{1-x^{*}}
$$

and

$$
y(1)=\frac{-x^{*}}{1-x^{*}} .
$$

Thus, the party would give itself an overwhelming majority $\left(\alpha_{j}=1\right)$ in a substantial minority $y(1)$ of the districts. The majority of the districts, a fraction $y\left(x^{*}\right)$ of them all, would be favorable to the the opposition, but, because of the frequency of large swings, only the party's seats would be safe; the opposition's seats would be frequently lost.

Other possibilities fot $H(z)$ will lead to different solutions for the optimal gerrymander $y$, but 
it seems unnecessary to consider all possible cases here since the case we have considered in the body of the text is far and away the most likely.

2. The lower court refused to give any weight to proposed assessments of baseline voting strength or predictions of probable election outcomes which had been offered in the case, and relied exclusively on the actual election results in 1982. The Supreme Court plurality asserted, however, that 'projected election results based on district boundaries and past voting patterns may certainly support this type of [gerrymandering] claim, even where no election has yet been held under the challenged districting' (106 S Ct at $2814, \mathrm{n} .17$, original emphasis).

\section{References}

BAKER, G. (1985). Electoral Laws and Their Political Consequences (B. Grofman and A. Lijphart, eds). New York: Agathon Press.

BACKSTROM, C., ROBNS, L. A.VD ELLER, S. (1978). Issues in gerrymandering: an exploratory measure of partisan gerrymandering applied to Minnesota. Minnesota Law Review 62, 1121-1159.

CAIN, B. E. (1984). Reapportionment Puzzle. Berkeley: University of California Press.

CAIN, B. E. (1985). Assessing the partisan eftects of redistricting. American Political Science Review 79(2), $320-333$.

Dahl, R. (1956). A Preface to Democratic Theory. Chicago: University of Chicago Press.

Dixon, R. G., JR (1971). The court, the people, and 'one man, one vote'. In Reapportionment in the 1970s (N. W. Polsby, ed.) pp. 7-45. Berkeley: University of California Press.

GOPOLAN, J. D. AND W'EST, D. M. (1984). Trading security for seats: strategic considerations in the redistricting process. Journal of Politics 46, 1080-1096.

Grofman, B. (1975). A review of macro-election systems. In German Political Yearbook (R. Wildenmann, ed.) Vol. 4, pp. 303-352. Munich: Verlag.

GrofMAN, B. (1982). Alternatives to single-member plurality districts: legal and empirical issues. Policy Studies Journal (1981), 9, Spccial Issue 3, 875-898. Reprinted in Representation and Redistricting Issues (B. Grofman, A. Lijphart, R. McKay and H. Scarrow, eds) pp. 107-128. Boston: Lexington Books.

GrofMAN, B. (1983). Measures of bias and proportionality in seats-votes relationships. Political Methodology 9 , $295-327$.

Grofman, B. (1984). Reformers, politicians, and the courts: a preliminary look at 1980 s reapportionment. Political Geography Quarterly 1(4), 303-316.

Grofman, B. (1985a). Introduction to minisymposium on Political Gerrymandering: Badham s. Eu, political science goes to court. PS, 538-543.

GROFMAN, B. (1985b). Grofman declarations in Badham v. Eu (excerpts). PS (summer), 544-549. 573-574.

Grofman, B. (1985c). Criteria for districting: a social science perspective. UCLA Law Review 33(1), 77-184.

Grofman, B. AND SCARrow, H. (1982). Current issues in reapportionment. Low and Politics Quarterly 4(4), $435-474$.

Grofman, B., Owen, G. ANd FeLd, S. (1983). Thirteen theorems in search of the truth. Theory and Decision $15,261-278$.

GudGin, R. AND TAyLoR, P. (1979). Seats, Votes and the Spatial Organization of Elections. London: Pion.

HARDY, L. C. (1977). Considering the gerrymander. Pepperdine Lou Review 4, 243-284.

LIJPHART, A. AND GROFMAN, B., EDS (1984). Choosing an Electoral System. New York: Praeger.

NEmi. R. AND DeEgan, J., JR (1978). Competition, responsiveness and the swing ratio. American Political Science Review 72, 1304-1323.

OWEN, G. AND GROFMAN, B. (1982). Collective representation and the seats-votes swing relationship. Presented at the Annual Meeting of the American Association of Geographers, San Antonio, Texas, April 22-28.

ROBERTSON, A. W. (1983). American redistricting in the 1980s: the effect on the mid-term elections. Electoral Studies 2, 113-129.

SCARROW, H. (1982a). The impact of reapportionment on party representations in the state of New York. In Representation and Redistricting Issues (B. Grofman, A. Lijphart, R. McKay and H. Scarrox; eds) pp. 223236. Boston: Lexington Press.

SCARrow, H. (1982b). Partisan gerrymandering-insidious or benevolent? Gaffney v. Cummings and its aftermath. Journal of Politics, 810 821.

SCHWAB, L. M. (1985). The impact of 1980 reapportionment in the United States. Political Geography Quarterly $4,141-158$ 
SiCKELS, R. J. (1966). Dragons, bacon strips, and dumbbells: who's afraid of reapportionment. Yale Law Journal $75,1300-1308$.

TLME (1981). 'One man, one vote, one mess: as states try to redistrict, recriminations-and fists-fly.' Time, July 13, p. 12.

TUFTE, E. R. (1973). The relationship between seats and votes in two-party systems. American Political Science Review 67, 540-547. 